\title{
Circadian hormone secretory profiles in women with severe premenstrual tension syndrome.
}

\author{
M. STEINER, R. F. HASKETT \& B. J. CARROLL Mental Health Research Institute, \\ University of Michigan, Ann Arbor
}

S. E. HAYS \& R. T. RUBIN Department of Psychiatry, UCLA Medical Center, California

\begin{abstract}
Summary. The circadian secretory profiles of serum prolactin, growth hormone and cortisol were measured in two women suffering from severe premenstrual tension syndrome and in two asymptomatic control subjects. Subjects and controls were screened and included after a rigorous selection process. Blood samples were obtained every $30 \mathrm{~min}$ over a period of $24 \mathrm{~h}$ in each woman both on day 9 (follicular phase) and day 26 (luteal phase) of the menstrual cycle. There was no relationship between the hormonal secretory profiles and the premenstrual tension syndrome.
\end{abstract}

Many biological theories have been suggested to explain the premenstrual tension syndrome (PMTS) (Steiner \& Carroll 1977). We have recently described the psychological changes that occur with severe PMTS (Haskett et al. 1980; Steiner et al. 1980), but the aetiological significance of the hormonal changes during the menstrual cycle is as yet unclear. The pattern of circulating sex steroid hormones and gonadotrophins in the course of the normal menstrual cycle have been well described in recent years (Punnonen et al. 1976; Kaulhausen et al. 1978). Studies which have attempted to demonstrate a link between PMTS and a relative imbalance of hormones, including not only oestrogens and progesterone but also aldosterone, have produced conflicting results (Smith 1975; Backstrom \& Mattsson 1975; Janowsky et al. 1973).

Earlier reports of elevated prolactin (PRL) levels during the late luteal phase in women with PMTS (Halbreich et al. 1976; Horrobin et al. 1976) have not been confirmed by other investigators (Backstrom \& Aakvaag 1981; Steiner et al. 1983a, b).

In the present study we measured the circadian secretory profile of PRL at two points in the menstrual cycle in two women with severe PMTS, and compared them with two asymptomatic

Correspondence: M. Steiner, McMaster Psychiatric Unit, St Joseph's Hospital, McMaster University, Hamilton, Ontario L8N1Y4, Canada. control subjects. In addition, we examined the secretory profiles of growth hormone $(\mathrm{GH})$ and cortisol to assess their relation to the severity of psychological distress and the possible contribution of a non-specific stress effect on these hormonal systems.

\section{Subjects and methods}

The project was approved by the Human Subject Review Committee of the University of Michigan and only subjects willing and able to give informed consent were included in the study.

Two women with extremely severe PMTS were carefully selected from a large group of volunteers. They were 28 and 30 years of age, with no recent change in gynaecological function and no significant physical or psychiatric disorder. They had taken no drugs for 1 month before the study and took none during the study. They had premenstrual dysphoric symptoms for at least six consecutive menstrual cycles. The 'Menstrual Distress Questionnaire-Today Form' (MDQ-T) (Moos 1969) was used to demonstrate severity of symptoms and the on/off nature of the disturbance. Two women, matched for age, who were completely asymptomatic volunteered to be studied as controls. Ovulation was investigated in all four subjects using basal body temperature charts for 1 month before, and throughout, the month of the study. 
The two subjects with PMTS and the two asymptomatic healthy controls were admitted to the clinical research centre for $24 \mathrm{~h}$ on days 9 and 26 of their menstrual cycle (where day 1 was the onset of menses). The studies on day 9 (follicular phase) preceded those on day 26 (late luteal phase) in all subjects. Blood samples for PRL, $\mathrm{GH}$ and cortisol were collected every $30 \mathrm{~min}$ for $24 \mathrm{~h}$ from an indwelling catheter in the antecubital vein. The severity or the absence of symptoms in each subject was established by completing the MDQ-T form on the morning of each study day. The MDQ lists 47 symptoms each scored on a scale from 1 to 6 (minimum total score of 47 to a maximum total score of 282) and the 'Today Form' (MDQ-T) is rated according to the symptoms present on the day of completing the scale.

Serum PRL was measured by an established double antibody radio-immunoassay technique (Sinha et al. 1973) with intra-assay variability of $8.9 \%$, inter-assay variability of $13.8 \%$ and sensitivity of $0.1 \mathrm{ng} / \mathrm{tube}$. Human PRL (hPRL, AFP 1562-C) for iodination and standard was kindly provided by $\mathrm{Dr}$ Albert F. Parlow. The glucose oxidase-lactoperoxidase method described by Tower et al. (1977) was used for iodination and the suitability of the ${ }^{125}$ I-PRL was verified by the talc-resin-TCA technique (Tower et al. 1978). Anti-hPRL (AFP-1) was supplied by the National Pituitary Agency. Values are reported as $\mathrm{ng} / \mathrm{ml}$ of hPRL AFP $1562-\mathrm{C}$ (see also Hays \& Rubin 1979).

GH was measured by a modified radioimmunoassay technique (Odell et al. 1967). Human GH standard preparation was HS-840; the iodination preparation was HS-1147-BC; and the GH antibody had no number designation. These materials were received from the National Pituitary Agency through the courtesy of $\mathrm{Dr}$ Albert F. Parlow. All samples were tested in duplicate, and samples from each subject were tested in the same assay. Mean intra-assay variability was $5 \%$ and mean inter-assay variability was $20 \%$. The $50 \%$ intercept and $(\mathrm{B} / \mathrm{T})_{0}$ (percentage bound in the absence of unlabelled hormone) values were well within the tolerance ranges for our laboratory.

Plasma cortisol was measured by the competitive protein-binding method of Murphy (1967) modified as described by Carroll et al. (1976).

The data were analysed statistically using an analysis of variance with repeated measures.

\section{Results}

The cortisol, GH and PRL circadian secretory profiles are presented in Figs 1-3. The mean daily serum levels for these three hormones and the corresponding MDQ-T scores are shown in Table 1.

The plasma cortisol levels showed a typical circadian secretory profile in the two subjects with PMTS and in the two controls on both occasions of sampling (Fig. 1). All eight cortisol profiles were well within normal limits as described by Krieger et al. (1971). The timing of the major circadian rise in cortisol secretion and the extent of spontaneous nocturnal inhibition of cortisol levels were similar in the follicular and late luteal phases. The one exception was the unexplained lack of nocturnal inhibition during the follicular phase in one of the controls (no. 3, D.F.D.). The mean daily plasma cortisol levels (Table 1) showed statistically significant differences between days 9 and 26 but the direction of change was not consistent in either the PMTS subjects or the controls and these differences probably have no physiological significance.

The growth hormone secretory profiles were not remarkably different between days 9 and 26 (Fig. 2). Nocturnal GH elevations were seen in each woman, as were some spontaneous diurnal peaks. The mean daily plasma GH levels are shown in Table 1. The mean differences between days 9 and 26 were weakly significant in one PMTS and in one control subject and although highly significant in the other control subject the change was in the opposite direction.

The prolactin secretory profiles are shown in Fig. 3. A general elevation of PRL values throughout the circadian cycle was found in all the four women in the late luteal (premenstrual) phase. In one woman with PMTS (no. 2, A.B.L., Fig. $3 b$ ) this increase was substantial and was recorded at a time when she had severe symptoms, with an extremely high MDQ-T total score of 194 (for comparative data see Moos 1968; Gruba \& Rohrbaugh 1975; Rouse 1978). A much smaller change was seen in the other woman with PMTS (no. 1, R.P.R., Fig. $3 a$ ) who was almost as symptomatic with a very high MDQ-T score of 171 .

It is notable that although both the asymptomatic control subjects denied any features of PMTS, confirmed by their low MDQ-T score control subject no. 4 (S.E.S., Fig. 3d) had 

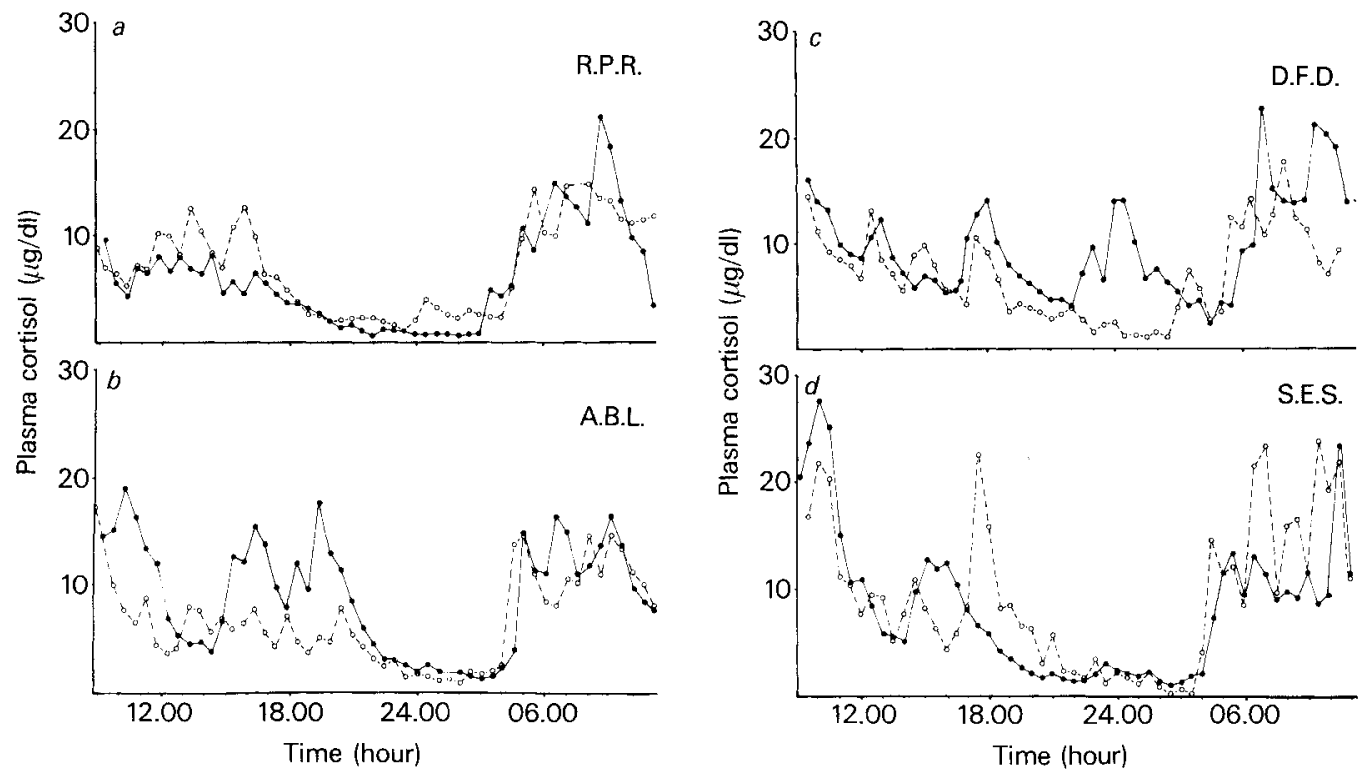

Fig. 1. Circadian cortisol profiles in two women with severe premenstrual tension syndrome $(a \& b)$ and two asymptomatic control subjects $(c \& d)$ during the follicular $(-\infty)$ and luteal $(0 \ldots \ldots)$ phases of the menstrual cycle.

marked elevation of PRL during the late luteal (premenstrual) phase.

Well-defined early morning maxima of PRL levels were present in only some women and were inconsistent between phases.

The mean daily PRL levels (Table 1) were significantly higher in the two women with PMTS during the late luteal phase but the most significant difference in the same direction was seen in one of the asymptomatic control subjects.

\section{Discussion}

The cortisol and GH results in our study do not indicate a major neuro-endocrine stress or arousal response associated with PMTS. The elevated

Table 1. Mean 24-h plasma levels of prolactin (PRL), growth hormone (GH) and cortisol in two women with severe premenstrual tension syndrome (PMTS) and two asymptomatic control subjects

\begin{tabular}{|c|c|c|c|c|c|}
\hline \multirow{2}{*}{ Subject } & \multirow{2}{*}{$\begin{array}{c}\text { Day } \\
\text { of } \\
\text { cycle }\end{array}$} & \multicolumn{3}{|c|}{ 24-h plasma levels } & \multirow{2}{*}{$\begin{array}{c}\text { MDQ-T } \\
\text { score }\end{array}$} \\
\hline & & PRL (ng/ml) & $\mathrm{GH}(\mathrm{ng} / \mathrm{ml})$ & Cortisol $(\mu \mathrm{g} / \mathrm{dl})$ & \\
\hline \multicolumn{6}{|l|}{ PMTS } \\
\hline \multirow[t]{2}{*}{ no. 1 (R.P.R.) } & 9 & $8 \cdot 0 \pm 0 \cdot 4$ & $1.92 \pm 0.95$ & $5.97 \pm 0.67$ & 63 \\
\hline & 26 & $11 \cdot 0 \pm 0 \cdot 7^{* * *}$ & $3 \cdot 27 \pm 0.85^{*}$ & $7.06 \pm 0.58^{* * *}$ & 171 \\
\hline \multirow[t]{2}{*}{ no. 2 (A.B.L.) } & 9 & $10 \cdot 5 \pm 0 \cdot 6$ & $1.14 \pm 0.26$ & $9.14+0.71$ & 76 \\
\hline & 26 & $25 \cdot 3 \pm 1 \cdot 1^{* * *}$ & $1 \cdot 69 \pm 0 \cdot 29 \mathrm{NS}$ & $6.89 \pm 0.59^{* * *}$ & 194 \\
\hline \multicolumn{6}{|l|}{ Control } \\
\hline \multirow[t]{2}{*}{ no. 3 (D.F.D.) } & 9 & $19 \cdot 1 \pm 0 \cdot 7$ & $2.46 \pm 0.59$ & $9.78 \pm 0.66$ & 48 \\
\hline & 26 & $20 \cdot 4 \pm 0 \cdot 6 \mathrm{NS}$ & $3 \cdot 90 \pm 1 \cdot 19^{*}$ & $7.00 \pm 0.57 * * *$ & 55 \\
\hline \multirow[t]{2}{*}{ no. 4 (S.E.S.) } & 9 & $29 \cdot 8 \pm 0 \cdot 8$ & $4 \cdot 43 \pm 1 \cdot 31$ & $8 \cdot 39 \pm 0.99$ & 74 \\
\hline & 26 & $49 \cdot 5 \pm 1 \cdot 0^{* * *}$ & $1 \cdot 92 \pm 0 \cdot 6^{* * *}$ & $9.40 \pm 0.97^{* *}$ & 59 \\
\hline
\end{tabular}

Results are mean \pm SEM.

Significance of differences: ${ }^{*} P<0.05 ;{ }^{* *} P<0.01 ;{ }^{* *} P<0.001$; NS, not significant.

MDQ-T, 'Menstrual Distress Questionnaire-Today'. 

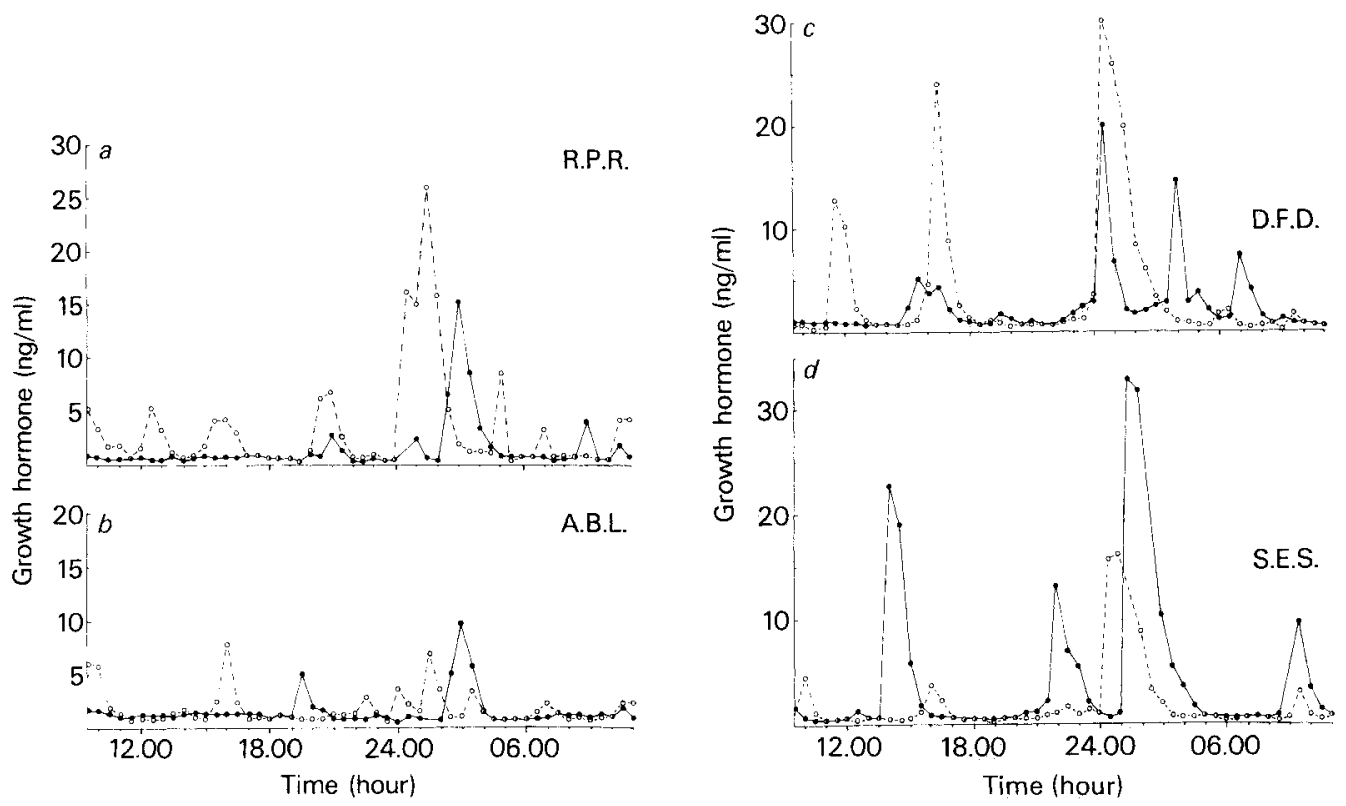

Fig. 2. Circadian growth hormone profiles in two women with severe premenstrual tension syndrome $(a \& b)$ and two asymptomatic control subjects $(c \& d)$ during the follicular - and luteal $(\bigcirc \ldots \ldots)$ phases of the menstrual cycle.
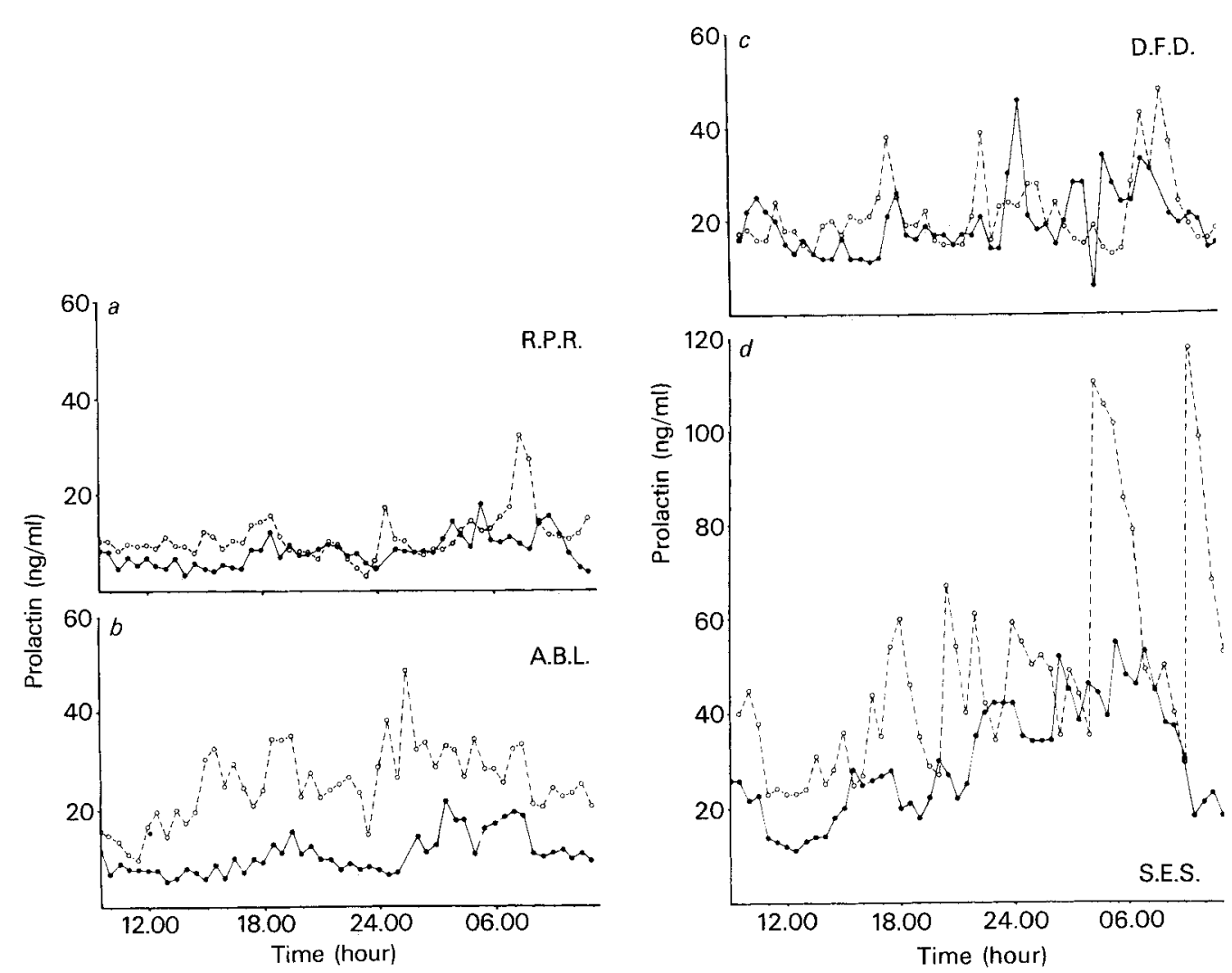

Fig. 3. Circadian prolactin profiles in two women with severe premenstrual syndrome $(a \& b)$ and two asymptomatic control subjects $(c \& d)$ during the follicular $(-\infty)$ ) and luteal $\left(\mathrm{O}_{-} \ldots\right)$ ) phases of the menstrual cycle. 
PRL levels are also unlikely to be the result of nonspecific stress of PMTS. We found no support for the hypothesis that PMTS is associated with hyperprolactinaemia (see also O'Brien \& Symonds 1982). Markedly elevated PRL levels were seen in the absence of PMTS.

It is clear from our data that measurement of circadian profiles is superior to plasma level estimation in single samples. The pulsatile secretion pattern of these hormones clearly demonstrates the difficulties of interpreting values obtained from single samples. We have also demonstrated that the comparison of mean daily hormone levels with behavioural observations that are scored once a day does not appear to be meaningful. The relation between changes in hormonal secretion and PMTS remains unclear.

\section{Acknowledgments}

This work was supported by PHS grant MH28294 and by the Mental Health Research Institute, University of Michigan. The authors thank Judith N. Osmun and James Ritchie for their important contributions to the clinical and laboratory aspects of this study and Christine McCulloch for her excellent technical assistance in preparing the manuscript.

\section{References}

Backstrom, T. \& Aakvaag, A. (1981) Plasma prolactin and testosterone during the luteal phase in women with premenstrual tension syndrome. Psychoneuroendocrinology 6, 245-251.

Backstrom, T. \& Mattsson, B. (1975) Correlation of symptoms in premenstrual tension to oestrogen and progesterone concentrations in blood plasma: a preliminary study. Neuropsychobiology i, 80-86.

Carroll, B.J., Curtis, G. C. \& Mendels, J. (1976) Neuroendocrine regulation in depression. II. Discrimination of depressed from nondepressed patients. Arch Gen Psychiatry 33, 105 1-1058.

Gruba, G. H. \& Rohrbaugh, M. (1975) MMPI correlates of menstrual distress. Psychosom Med 37, 265-273.

Halbreich, U., Assael, M., Ben-David, M. \& Bornstein, R. (1976) Serum prolactin in women with premenstrual syndrome. Lancet ii, 654-658.

Haskett, R. F., Steiner, M., Osmun, J. N. \& Carroll, B. J. (1980) Severe premenstrual tension: delineation of the syndrome. Biol Psychiatry 15, 121-139.

Hays, R. T. \& Rubin, S. E. (1979) Variability of prolactin response to intravenous and intramuscular haloperidol in normal adult men. Psychopharmacology 61, 17-24.
Horrobin, D. F., Karmali, R. A., Mtabaji, J. P., Manku, M. S. \& Nassar, B. A. (1976) Prolactin and mental illness. Postgrad Med J 52, (Suppl. 3), 79-85.

Janowsky, D. S., Berens, S. C. \& Davis, J. M. (1973) Correlations between mood, weight and electrolytes during the menstrual cycle: A renin-angiotensin-aldosterone hypothesis of premenstrual tension. Psychosom Med 35, 143-154.

Kaulhausen, H., Leyendecker, G., Benker, G. \& Breuer, H. (1978) The relationship of the renin-angiotensin--aldosterone system to plasma gonadotropin, prolactin and ovarian steroid patterns during the menstrual cycle. Arch Gynaekol 225, 179-200.

Krieger, D. T., Allen, W., Rizzo, F. \& Krieger, H. P. (1971) Characterization of the normal temporal pattern of plasma corticosteroid levels. $J$ Clin Endocrinol Metab 32, 266-284.

Moos, R. H. (1968) The development of a Menstrual Distress Questionnaire. Psychosom Med 30, 853 867.

Moos, R. H. (1969) Menstrual Distress Questionnaire. Preliminary Manual Social Ecology Lab., Stanford, California.

Murphy, B. E. P. (1967) Some studies of the proteinbinding of steroids and their application to the routine micro and ultramicro measurement of various steroids in body fluids by competitive protein-binding radioassay. $J$ Clin Endocrinol Metab 27, 973-990.

O'Brien, P. M. S. \& Symonds, E. M. (1982) Prolactin levels in the premenstrual syndrome. $\mathrm{Br} J$ Obstet Gynaecol 89, 306-308.

Odell, W. D., Rayford, P. L. \& Ross, G. T. (1967) Simplified, partially automated method for radioimmunoassay of human thyroid-stimulating, growth, luteinizing, and follicle stimulating hormones. J Lab Clin Med 70, 973-980.

Punnonen, R., Nummi, S., Ylikorkala, O., Alapiessa, U., Karvonen, P. \& Viinikka, L. (1976) A composite picture of the normal menstrual cycle. Acta Obstet Gynecol Scand Suppl 51, 63-70.

Rouse, P. (1978) Premenstrual tension: a study using the Moos Menstrual Questionnaire. J Psychosomat Res 22, 215-222.

Sinha, Y. N., Selby, F. B., Lewis, U. J. \& Vander-Laan, W. P. (1973) A homologous radioimmunoassay for human prolactin. $J$ Clin Endocrinol Metab 36, 509516.

Smith, S. L. (1975) Mood and the menstrual cycle. In Topics in Psychoendocrinology (Sachar, E. J., Ed.), Grune \& Stratton, New York, pp. 19-58.

Steiner, M. \& Carroll, B. J. (1977) The psychobiology of premenstrual dysphoria: review of theories and treatments. Psychoneuroendocrinology 2, 321-335.

Steiner, M., Haskett, R. F. \& Carroll, B. J. (1980) Premenstrual tension syndrome: the development of 
research diagnostic criteria and new rating scales. Acta Psychiatrica Scand 62, 177-190.

Steiner, M., Haskett, R. F., Carroll, B. J., Hays, S. E. \& Rubin, R. T. (1983a) Plasma prolactin and severe premenstrual tension. Psychoneuroendocrinology in press.

Steiner, M., Haskett, R. F., Osmun, J. N., Starkman, M. N., Peterson, E., Metski, R. \& Carroll, B. J. (1983b) The treatment of severe premenstrual dysphoria with bromocriptine. I Psychosom Obstet Gynaecol 2, 223-227.
Tower, B. B., Clark, B. R. \& Rubin, R. T. (1977) Preparation of ${ }^{125} I$ polypeptide hormones for radioimmunoassay using glucose oxidase with lactoperoxidase. Life Sci 21 , 959-966.

Tower, B. B., Sigel, M. B., Rubin, R. T., Poland, R. D. \& Vander-Laan, W. P. (1978) The talc-resin-TCA test: rapid screening of radioiodinated polypeptide hormones for radioimmunoassay. Life Sci 23, 2183-2192.

Received 18 July 1983

Accepted 7 September 1983 